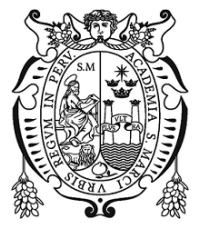

Revista de Investigación de Física 23(2), (Jul-Dic 2020)

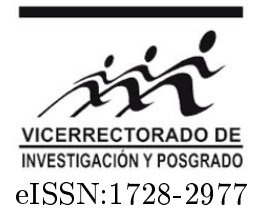

\title{
Editorial: Los investigadores de la Facultad de Ciencias Físicas, UNMSM
}

\author{
César Jiménez ${ }^{* 1}$ \\ ${ }^{1}$ Universidad Nacional Mayor de San Marcos, Lima, Perú
}

Lima, 01 de junio de 2020

De acuerdo a la Ley Universitaria 30220, la universidad en el Perú tiene como objetivos: docencia, investigación y reponsabilidad social (art. 3). También, dicha ley define la categoría del Docente Investigador RENACYT, como aquel docente que realiza investigación, con una bonificación adicional del $50 \%$ de su haber (art. 86).

Ser un investigador implica: 1) Formar parte de un grupo de investigación y participar en proyectos de investigación con financiamiento interno o externo, 2) Formar nuevos cuadros mediante la asesoría de tesistas de pregrado y posgrado. 3) Publicar los resultados de la investigación en revistas indexadas.

La publicación (en una revista arbitrada e indexada) es la culminación del proyecto de investigación. De manera que, si se lleva a cabo un proyecto de investigación y sólo se presenta un Informe Técnico Final, la investigación aún estaría inconclusa. En los círculos académicos, es célebre la frase "publica o muere".

Existen dos indicadores para cuantificar el impacto de las publicaciones: el número de citaciones y el índice $H$. Si tuviera varias publicaciones y pocas citaciones, significa que mi trabajo no es relevante, por lo tanto, debería pensar seriamente en cambiar de área de investigación.

El índice $H$ es un indicador que combina el número de publicaciones con el número de citaciones. Por ejemplo, si tuviera una publicación con al menos una citación, entonces mi índice $H$ sería 1 ; si tuviera dos publicaciones con al menos dos citaciones cada una, mi índice $H$ sería 2, y así sucesivamente. Por lo general, el índice $H$ se incrementa con el paso de los años.

De acuerdo a los estándares del Concytec (https: //portal . concytec .gob.pe), los investigadores del Grupo Carlos Monge se clasifican en 4 categorías: I (el más alto), II, III y IV (doctores jóvenes). Cada una de estás categorías tiene sus requisitos respectivos. Por ejemplo, para ser considerado como un investigador de primer nivel (A1), además de tener el grado académico de Doctor, debe haber publicado 40 artículos como mínimo en revistas indexadas en bases relevantes como Scopus o Web of Science.

\footnotetext{
*cjimenezt@unmsm.edu.pe
}

\begin{tabular}{llcccc}
\hline$N$ & Investigador & Año & Pub & Cit & $H$ \\
\hline 1 & Bustamante, Ángel & 2020 & 73 & 906 & 14 \\
2 & García, Víctor & 2019 & 59 & 645 & 14 \\
2 & Landauro, Carlos & 2019 & 33 & 271 & 9 \\
4 & Peña, Víctor & 2019 & 26 & 119 & 5 \\
5 & Quispe, Justiniano & 2020 & 24 & 082 & 6 \\
6 & Rojas, Chachi & 2019 & 15 & 043 & 4 \\
7 & Jiménez, César & 2020 & 12 & 111 & 5 \\
8 & Reyes, Felipe & 2017 & 11 & 018 & 2 \\
9 & Lozano, Whualker & 2013 & 10 & 176 & 9 \\
10 & Ramos, Juan & 2020 & 10 & 158 & 6 \\
\hline
\end{tabular}

Tabla 1: Ranking de investigadores de la Facultad de Ciencias Físicas, UNMSM. Año: último año que publicó, Pub: número de publicaciones, Cit: número de citaciones, $H$ : índice $\mathrm{H}$ (Datos de Scopus: https://www.scopus.com).

De acuerdo a los estándares del CONCYTEC y a los datos públicos de Scopus, se ha elaborado un ranking de investigadores de la Facultad de Ciencias Físicas (Tabla 1), ordenado de acuerdo al número de publicaciones. Sólo se presenta a los 10 primeros investigadores, quienes han publicado en los últimos 10 años.

En la Facultad de Ciencias Físicas, sólo hay dos investigadores de primer nivel (A1): Ángel Bustamante y Víctor García. El resto de los investigadores está en carrera ascendente o en vías de extinción.

Analizando el índice $H$, las publicaciones de Felipe Reyes no son muy relevantes $(H=2)$; sin embargo, las publicaciones de Whualker Lozano son muy relevantes, a pesar que tiene menos publicaciones que Felipe Reyes.

De acuerdo al último año de publicación, hay un investigador en vía de retomar la investigación: Whualker Lozano, quien en los últimos 7 años, no ha realizado ninguna publicación indexada en Scopus o Web of Science.

Estos resultados sirven para que los investigadores continuen en carrera ascendente y no se duerman en sus laureles. Por lo que es pertinente recordar siempre la frase: "PUBLICA O MUERE". 